\title{
Association of proinsulin-like molecules with lipids and fibrinogen in non-diabetic subjects - evidence against a modulating role for insulin
}

\author{
V.Mohamed-Ali ${ }^{1}$, M.M. Gould ${ }^{2}$, S. Gillies ${ }^{1}$, S. Goubet ${ }^{2}$, J.S. Yudkin ${ }^{1}$, A.P. Haines ${ }^{2}$ \\ ${ }^{1}$ Department of Medicine, University College London Medical School, Whittington Hospital, London, UK \\ ${ }^{2}$ Department of Primary Health Care, University College London Medical School, Whittington Hospital, London, UK
}

Summary Elevated concentrations of proinsulin-like molecules, other than insulin, may be associated with abnormalities of cardiovascular risk factors, promoting atherogenesis and thrombosis. Using specific assays we examined the relationship of levels of insulin, intact proinsulin and des-31,32 proinsulin to blood pressure, lipids, fibrinogen, factor VII and albumin excretion rate in 270 europids with normal glucose tolerance. After correcting for age and body mass index, fasting and 2 -h insulin concentrations were significantly associated with those of total and LDL-cholesterol $(r=0.18-0.22)$, HDL-cholesterol (both $r=-0.20)$ and triglycerides $(r=0.21$ and 0.18 ), but not with blood pressure. Concentrations of intact and des-31,32 proinsulin showed significant associations with those of total and LDL-cholesterol $(r=0.20-0.23)$, HDL-cholesterol $(r=-0.31$ and $-0.32)$ and triglycerides $(r=0.22$ and 0.26$)$. Fasting insulin and intact proinsulin concentrations were significantly associated with fibrinogen $(r=0.15$ and 0.18$)$. Concentrations of proinsulin-like molecules comprised less than $10 \%$ of all insulin-like molecules, and so were calculated not to influence previously described relationships between insulin concentrations and cardiovascular risk factors measured using nonspecific assays. In multiple regression analyses des31,32 proinsulin concentration was more strongly associated with those of HDL-cholesterol (negatively), LDL-cholesterol and triglycerides than fasting insulin concentrations, while intact proinsulin replaced insulin concentrations in their relationships with fibrinogen. Our results show correlations between dyslipidaemia and proinsulin-like molecules at concentrations at which biological, insulin-like, activity appears unlikely. We also show relationships between LDL-cholesterol and fibrinogen and the proinsulinlike molecules. These results suggest that a causal relationship mediated by hyperinsulinaemia and insulin resistance is unlikely. [Diabetologia (1995) 38: 1110-1116]

Key words Proinsulin-like molecules, cardiovascular risk factors, insulin, insulin resistance, beta-cell function.
The relationship between fasting hyperinsulinaemia and certain cardiovascular risk factors, such as blood pressure, raised triglycerides and low concentrations of HDL-cholesterol, has been demonstrated in both

Received: 29 August 1994 and in final revised form: 5 June 1995

Corresponding author: Ms. V. Mohamed-Ali, Department of Medicine, University College London Medical School, "G" Block, Archway Wing, Whittington Hospital, Archway Road, London N 19 3UA, UK

Abbreviations: PAI-1, Plasminogen activator inhibitor-1; PI, proinsulin; $\mathrm{CV}$, coefficient of variation diabetic and non-diabetic subjects $[1,2]$. We have reported that in diabetic subjects the apparent association between concentrations of insulin and these risk factors may be explained by the proinsulin-like molecules, intact and des-31,32 proinsulin [3], which crossreact in most immunoassays for insulin [4]. These observations raise the possibility that elevated concentrations of proinsulin-like molecules, rather than insulin, may produce abnormalities of cardiovascular risk factors, thereby promoting atherogenesis and thrombosis. Because previous studies have not applied highly sensitive and specific assays $[5,6]$, to date no epidemiological study in non-diabetic sub- 
jects has related levels of cardiovascular risk factors to concentrations of intact proinsulin and des-31,32 proinsulin, the main circulating insulin precursors. We have therefore studied the relationships of insulin, intact proinsulin and des-31,32 proinsulin, measured with such assays, with recognised cardiovascular risk factors in europid subjects, aged $40-75$ years with normal glucose tolerance, in north London.

The aims of the study were to determine for the first time, whether independent relationships exist between levels of cardiovascular risk factors and concentrations of each of the two major proinsulin-like molecules, measured using highly sensitive and specific assays, in non-diabetic subjects; and, secondly, to see whether in these subjects cross-reaction of these proinsulin-like molecules in standard assays for insulin would be likely to account for the previously described relationships of hyperinsulinaemia in such non-diabetic subjects.

\section{Subjects and methods}

Subjects. Details of subject recruitment and screening procedure have been reported elsewhere [7]. The study population consisted of 1046 europid subjects, aged 40-75 years, registered at a general practice in north London. Of these subjects 44 were not europid, 2 were over 75 years, 7 had glucose concentration data missing, 25 were newly diagnosed diabetic patients and 49 had impaired glucose tolerance, leaving 919 subjects ( 518 female and 401 male) with normal glucose tolerance [8]. A stratified subset of these subjects $(n=270,150$ female and 120 male) had fasting intact and des-31,32 proinsulins measured, this group being similar to the total population in terms of the characteristics shown in Table 1 and all subsequent analyses were carried out on this subset population.

Clinical methods. Blood pressure was measured with a random zero sphygmomanometer (Hawksley Gelman, Lancing, Sussex, UK) on two occasions, the first after registration and the second during the oral glucose tolerance test. Diastolic blood pressure was taken as the fifth Korotkoff sound. The mean of the two measurements was used in the analyses. Body mass index (BMI) was calculated as the weight $(\mathrm{kg})$ divided by the square of the height $\left(\mathrm{m}^{2}\right)$.

Venous blood $(20 \mathrm{ml})$ was taken after an overnight fast for measurements of plasma glucose, lipids, fibrinogen, factor VII and the insulin-like molecules. A glucose load (75 g: Fortical, Cow and Gate, Trowbridge, Wiltshire, UK) was then given and further blood samples were taken after $2 \mathrm{~h}$ for estimation of concentrations of plasma glucose and of insulin. Subjects provided two timed urine collections, one during the $2 \mathrm{~h}$ of the glucose tolerance test and the other as a timed overnight sample, for measurement of albumin excretion rate.

Biochemical methods. Plasma glucose concentration was assayed with glucose oxidase reagent (Beckman, Brea, Calif., USA). Serum triglycerides and total cholesterol were assayed enzymatically with commercial reagents (total-cholesterol: Boehringer-Mannheim, Lewes, Sussex, UK and triglycerides: Roche Diagnostics, Hatfield, Herts., UK). HDL-cholesterol was measured by the same method after the low density lipoproteins had been quantitatively precipitated out by the addi- tion of phosphotungstic acid in the presence of magnesium ions. LDL-cholesterol was calculated using the Friedewald formula [9]. Fibrinogen concentration was measured using a modified Clauss method (Boehringer-Mannheim) and factor VII activity assessed utilising factor-VII-deficient plasma (Withington Hospital, Manchester, UK). Urinary albumin concentration was measured by an in-house modified, competitive enzymoimmunoassay, validated against a commercial radioimmunoassay [7, 10] (Pharmacia-LKB, Milton Keynes, Bucks, UK) $(r=0.96)$ from which an albumin excretion rate was calculated.

Insulin, intact proinsulin and des-31,32 proinsulin concentrations were assayed by in-house two-site immunometric assays $[11,12]$ with previously characterised monoclonal antibodies 14B, 3 B 1 and A6 (Serono-Diagnostics, Woking, Surrey, UK) and an anti-C-peptide antibody, PEP001 (Novo Nordisk, Copenhagen, Denmark) [13]. Insulin was captured with $14 \mathrm{~B}$ and detected with $3 \mathrm{~B} 1$-alkaline phosphatase conjugate, using the amplification system described by Johannsson et al. [14]. The assay detected down to $3 \mathrm{pmol} \times \mathrm{1}^{-1}$ with intra- and inter-assay coefficients of variations (CVs) of 7.9 and $14.3 \%$ respectively [11]. Microplate immunoradiometric assays (IRMA) for intact proinsulin and des-31,32 proinsulin used 3B1 as the capture antibody, a sandwich formed with intact or des-31,32 proinsulin and detection with iodinated A6 or PEP001, respectively, and the radioactivity of individual wells was counted. Detection limits (mean +3 SD of zero signal) for intact and des-31,32 proinsulin were 0.25 and $0.125 \mathrm{pmol} \times \mathrm{l}^{-1}$, respectively. Intra- and inter-assay CVs were 6.3 and $9.8 \%$ for intact proinsulin and 8.6 and $12.6 \%$ for des-31,32 proinsulin, respectively [12]. Des-31,32 proinsulin concentration was calculated by subtracting the cross-reactivity of measured intact proinsulin. Insulin standard was supplied by NIBSC (Potters Bar, Herts., UK) and intact and des-31,32 proinsulin by Eli Lilly \& Co. (Indianapolis, Ind., USA).

\section{Statistical analysis}

The data were entered into a computer database using Smartware II software package and analysed using the Statistical Package for Social Sciences (SPSS). Insulin, intact proinsulin, des-31,32 proinsulin, factor VII and triglyceride concentrations and albumin excretion rate were log transformed to improve normality. The Kolmogorov-Amirnov test, which uses the hypothesis of normal distribution, was accepted for logtransformed data. Correlation coefficients and partial correlation coefficients were used to assess the strength of independent associations between different variables and concentrations of insulin and the proinsulin-like molecules while correcting for confounding variables. Correlations were repeated using a non-parametric (Spearman rank) test and there were virtually no differences in coefficients for any of the relationships. Furthermore, inspection of relationships using quintiles of distribution did not suggest threshold effects in the relationships. Separate multiple regression analyses for associations of intact and des-31,32 proinsulin molecules were performed on the subset of subjects for whom all variables were complete $(n=218)$. The association of BMI with insulin-like molecules was different in males and females and this was corrected for by using an interaction term (sex*BMI) in all subsequent analyses. There were missing data for blood pressure, fibrinogen, factor VII, lipids, insulin and 2-h albumin excretion rate for up to 12 subjects ( $4.5 \%$ ), but overnight and mean albumin excretion rate were unavailable for up to 40 subjects $(15 \%)$. Individual $n$ values are not presented for reasons of simplicity. 
Table 1. Characteristics of the subset population

\begin{tabular}{|c|c|c|c|}
\hline & $\begin{array}{l}\text { Men } \\
n=120)\end{array}$ & $\begin{array}{l}\text { Women } \\
n=150\end{array}$ & $p$-value \\
\hline Age (years) & $53.9 \pm 10.1$ & $54.5 \pm 10.3$ & NS \\
\hline Body mass index $\left(\mathrm{kg} \times \mathrm{m}^{2}\right)$ & $25.3 \pm 3.9$ & $25.6 \pm 4.9$ & NS \\
\hline Systolic blood pressure (mmHg) & $119.6 \pm 19.1$ & $116.6 \pm 20.6$ & 0.02 \\
\hline Diastolic blood pressure (mmHg) & $71.6 \pm 11.4$ & $67.8 \pm 10.6$ & $<0.001$ \\
\hline Fasting blood glucose $\left(\mathrm{mmol} \times \mathrm{l}^{-1}\right)$ & $4.9 \pm 0.5$ & $4.8 \pm 0.5$ & 0.02 \\
\hline 2-h blood glucose $\left(\mathrm{mmol} \times 1^{-1}\right)$ & $4.7 \pm 1.2$ & $4.8 \pm 1.1$ & NS \\
\hline Fibrinogen $\left(\mathrm{g} \times 1^{-1}\right)$ & $2.8 \pm 0.7$ & $2.9 \pm 0.8$ & NS \\
\hline Factor VII (\% act.) $)^{a}$ & $60.6 \pm 1.5$ & $65.3 \pm 1.4$ & 0.003 \\
\hline Total cholesterol $\left(\mathrm{mmol} \times \mathrm{l}^{-1}\right)$ & $6.2 \pm 1.2$ & $6.6 \pm 1.4$ & $<0.001$ \\
\hline HDL-cholesterol $\left(\mathrm{mmol} \times 1^{-1}\right)$ & $1.3 \pm 0.4$ & $1.6 \pm 0.4$ & $<0.001$ \\
\hline LDL-cholesterol $\left(\mathrm{mmol} \times \mathrm{l}^{-1}\right)$ & $4.2 \pm 1.2$ & $4.4 \pm 1.3$ & 0.008 \\
\hline Triglyceride $\left(\mathrm{mmol} \times \mathrm{l}^{-1}\right)^{\mathrm{a}}$ & $1.2 \pm 1.3$ & $1.3 \pm 1.6$ & 0.005 \\
\hline Fasting insulin $\left(\mathrm{pmol} \times \mathrm{1}^{-1}\right)^{\mathrm{a}}$ & $41.2 \pm 2.1$ & $46.8 \pm 1.8$ & 0.01 \\
\hline $2-\mathrm{h}$ insulin $\left(\mathrm{pmol} \times \mathrm{l}^{-1}\right)^{\mathrm{a}}$ & $132.7 \pm 2.4$ & $163.9 \pm 2.1$ & $<0.001$ \\
\hline Intact proinsulin $\left(\mathrm{pmol} \times 1^{-1}\right)^{\mathrm{a}}$ & $2.9 \pm 1.9$ & $2.5 \pm 1.7$ & 0.05 \\
\hline Des-31,32 proinsulin $\left(\mathrm{pmol} \times \mathrm{I}^{-1}\right)^{\mathrm{a}}$ & $1.6 \pm 2.1$ & $1.3 \pm 1.9$ & 0.02 \\
\hline 2-h albumin excretion rate $\left(\mu \mathrm{g} \times \min ^{-1}\right)^{\mathrm{a}}$ & $4.5 \pm 3.2$ & $4.0 \pm 2.9$ & NS \\
\hline Overnight albumin excretion rate $\left(\mu \mathrm{g} \times \min ^{-1}\right)^{a}$ & $3.1 \pm 3.4$ & $2.4 \pm 2.9$ & 0.001 \\
\hline Mean albumin excretion rate $\left(\mu \mathrm{g} \times \mathrm{min}^{-1}\right)^{\mathrm{a}}$ & $3.7 \pm 2.8$ & $3.0 \pm 2.4$ & 0.006 \\
\hline
\end{tabular}

Data are arithmetic means $\pm \mathrm{SD}$ and ${ }^{\mathrm{a}}$ Geometric means $\times / \div \mathrm{SD}$

\section{Results}

Of the normal glucose tolerant women screened $30 \%$ were pre-menopausal, $60 \%$ post-menopausal, $8 \%$ on hormone replacement therapy and $2 \%$ on the oral contraceptive pill.

Characteristics of the study populations are shown in Table 1. The men in the study had higher blood pressure and fasting glucose levels than the women. Total cholesterol, HDL-cholesterol, LDL-cholesterol, triglyceride and factor VII levels were higher in women and they were more hyperinsulinaemic as assessed by the fasting and 2-h samples. The men had higher intact and des-31,32 proinsulin concentrations than the women. The fasting concentrations of all the insulin-like molecules showed significant correlations with age, BMI, systolic and diastolic blood pressure, fasting and 2-h plasma glucose, fibrinogen and all measures of lipids (Table 2). There was no association between any of the measures of albumin excretion rate (2-h, overnight or logarithmic mean) and fasting or 2-h insulin while the association of intact and des-1,32 proinsulin levels and the 2 -h albumin excretion rate was just significant.

We have previously shown [4] that radioimmunoassays for insulin appear to recognise intact and desproinsulins. We therefore repeated correlations using the sum of fasting insulin plus intact proinsulin plus des-1,32 proinsulin in order to see whether, in non-diabetic subjects, concentrations of proinsulinlike molecules would confound relationships with insulin by using a non-specific assay. All correlations of sum of insulin-like molecules were, however, virtually identical to those using fasting insulin concentrations alone (data not shown).
Correlations, corrected for age, BMI, sex and the interaction (sex*BMI), are shown in Table 3. Adjustments for menopausal status or hormone replacement therapy were without effect on the results and therefore are not shown. All lipid variables showed significant correlation with all insulin and proinsulin concentrations (total and LDL-cholesterol and triglyceride positively; HDL-cholesterol negatively). Fibrinogen correlated significantly with fasting insulin and with intact proinsulin. There were no significant associations between any of the measures of albumin excretion rate and any of the insulin-like molecules.

Because of the possibility that relationships of insulin-like molecules with LDL-cholesterol were the result of a significant association between LDL-cholesterol and triglyceride $(r=0.29)$ the multiple regression analysis was repeated including triglyceride in the equation. Independent relations of LDL-cholesterol remained significant with intact proinsulin $(r=0.13)$ and des-31,32 proinsulin concentrations $(r=0.16)$, but not with fasting or 2-h insulin.

Separate multiple regression analysis models were used for intact and des-31,32 proinsulin submitting as independent variables concentrations of fasting insulin, intact proinsulin, des-31,32 proinsulin, age, sex, $\mathrm{BMI}$ and interaction (sex*BMI), and using in turn each of the lipids or fibrinogen as the dependent variables (Table 4 and 5, respectively). The significance level for entry in the multiple regression was 0.05 . The variables that entered the model, and those that did not, are presented in Tables 4 and 5. Small differences in partial correlation coefficients between Tables 3 and 4 are the consequence of using only 218 subjects for whom all variables were available in $\mathrm{Ta}$ ble 4 and 5. Des-31,32 proinsulin showed the strong- 
Table 2. Correlations of concentrations of insulin and proinsulin-like molecules in 270 subjects to cardiovascular risk factors

\begin{tabular}{|c|c|c|c|c|}
\hline Variables & Ins 0 & Ins 2 & Intact PI & Des-31,32 PI \\
\hline Age & $0.13^{\mathrm{a}}$ & $0.22^{\mathrm{b}}$ & $0.36^{\mathrm{c}}$ & $0.26^{c}$ \\
\hline Body mass index & $0.24^{\mathrm{c}}$ & $0.21^{\mathrm{b}}$ & $0.35^{\mathrm{c}}$ & $0.32^{\mathrm{c}}$ \\
\hline Systolic blood pressure & $0.15^{\mathrm{a}}$ & 0.11 & $0.32^{\mathrm{c}}$ & $0.25^{\mathrm{c}}$ \\
\hline Fasting plasma glucose & $0.24^{\mathrm{c}}$ & $0.21^{b}$ & $0.33^{\mathrm{c}}$ & $0.34^{\mathrm{c}}$ \\
\hline $2-\mathrm{h}$ plasma glucose & $0.22^{\mathrm{b}}$ & $0.49^{c}$ & $0.22^{\mathrm{b}}$ & $0.20^{\mathrm{b}}$ \\
\hline Fibrinogen & $0.22^{b}$ & $0.14^{\mathrm{a}}$ & $0.22^{b}$ & $0.17^{\mathrm{a}}$ \\
\hline HDL-cholesterol & $-0.22^{b}$ & $-0.19^{b}$ & $-0.36^{\mathrm{c}}$ & $-0.37^{\mathrm{c}}$ \\
\hline LDL-cholesterol & $0.25^{\mathrm{c}}$ & $0.27^{\mathrm{c}}$ & $0.28^{\mathrm{c}}$ & $0.28^{\mathrm{c}}$ \\
\hline Triglyceride & $0.27^{\mathrm{c}}$ & $0.25^{\mathrm{c}}$ & $0.32^{c}$ & $0.34^{\mathrm{c}}$ \\
\hline 2-h albumin excretion rate & 0.10 & 0.09 & $0.16^{\mathrm{a}}$ & $0.16^{\mathrm{a}}$ \\
\hline Overnight albumin excretion rate & 0.02 & 0.07 & 0.06 & 0.06 \\
\hline
\end{tabular}

${ }^{\mathrm{a}} p<0.05 ;{ }^{\mathrm{b}} p<0.01 ;{ }^{\mathrm{c}} p<0.001$; Ins 0 , Fasting insulin concentration; Ins 2, 2-h insulin concentration; Intact PI, fasting intact proinsulin concentration; Des,31-32 PI fasting des-31,32 proinsulin concentration

Table 3. Partial correlation coefficients of concentrations of insulin and proinsulin-like molecules in 270 subjects after adjusting for age, body mass index, sex and interaction (sex*BMI)

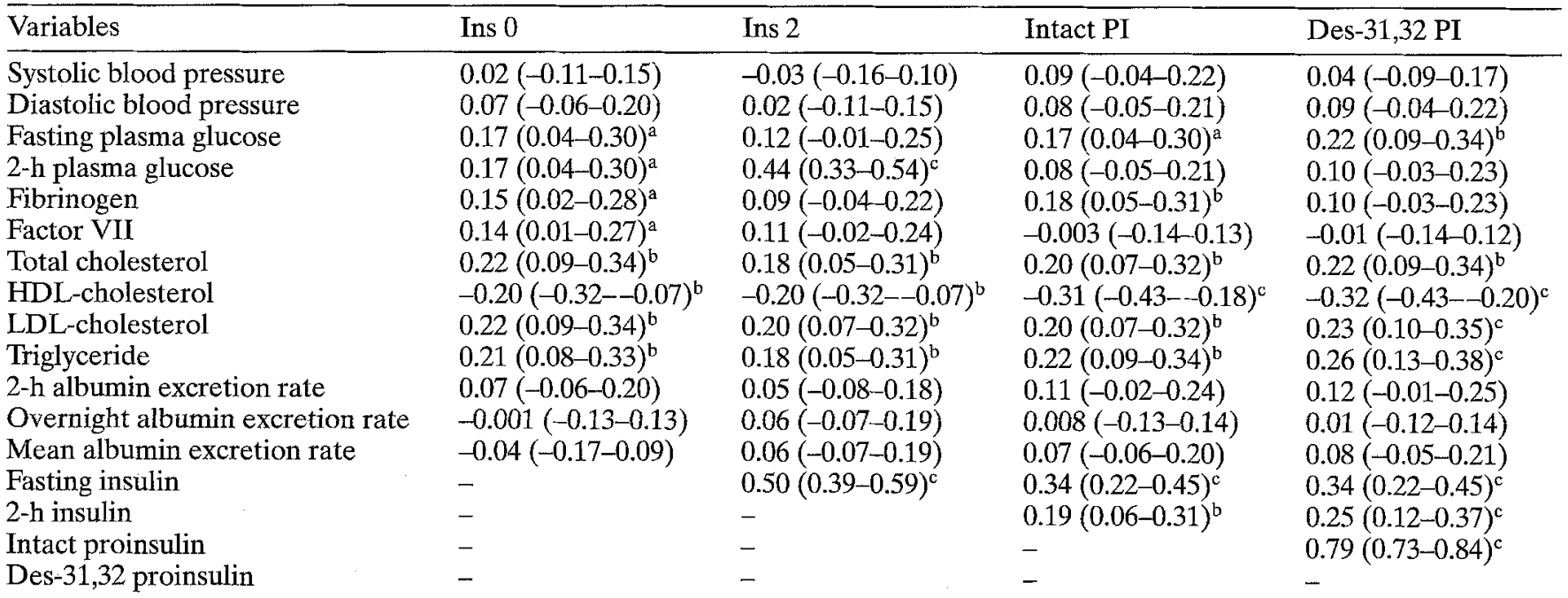

${ }^{\mathrm{a}} p<0.05 ;{ }^{\mathrm{b}} p<0.01 ;{ }^{\mathrm{c}} p<0.001$. Ins 0 , Fasting insulin concentration; Ins 2,2 -h insulin concentration; Intact PI, fasting intact proinsulin concentration; Des-31,32 PI, fasting des-31,32 proinsulin concentration

Partial correlation coefficients are shown with $95 \%$ confidence intervals

est relationships with HDL-cholesterol (negatively), LDL-cholesterol and triglycerides, while intact proinsulin replaced fasting insulin in the association with fibrinogen. In this population, it should be noted, we found no relationship between height and proinsulin concentrations.

\section{Discussion}

Obesity, hypertension, dyslipidaemia and glucose intolerance often coexist in the same individual, and this has been termed the insulin resistance syndrome, or syndrome $X[15,16]$. It has been proposed that the combination of the components of syndrome $\mathrm{X}$ may be mediated by insulin resistance, which, in the presence of a normally functioning pancreas, is associated with hyperinsulinaemia. Various mechanisms have been proposed whereby insulin resistance and increased circulating insulin concentrations might produce changes in cardiovascular risk factors. Body sodium and volume expansion may play a role in hypertension as insulin reduces urinary sodium excretion and increases sodium reabsorption 
Table 4. Multiple regression analyses of relationship between concentrations of fasting insulin and intact proinsulin with lipids and fibrinogen in 218 subjects

\begin{tabular}{llllll}
\hline $\begin{array}{l}\text { Dependent } \\
\text { variable }\end{array}$ & Explanatory variables & & $r$ & $\begin{array}{l}\text { percentage } \\
\text { change in } r^{2}\end{array}$ & $p$ \\
\hline Fibrinogen & In the equation & Intact PI & 0.18 & 3 & $\mathrm{r}^{2}=0.09$ \\
& Not in the equation & Fasting insulin & 0.09 & - & $p=0.0009$ \\
Total cholesterol & In the equation & Fasting insulin & 0.22 & 4.5 & $r^{2}=0.13$ \\
& & Intact PI & 0.14 & 1.6 & $p<0.0001$ \\
HDL & In the equation & Intact PI & -0.31 & 8.2 & $r^{2}=0.26$ \\
& Not in the equation & Fasting insulin & -0.10 & - & $p<0.0001$ \\
LDL & In the equation & Fasting insulin & 0.22 & 4.3 & $r^{2}=0.13$ \\
& & Intact PI & 0.13 & 1.6 & $p<0.0001$ \\
Triglycerides & In the equation & Intact PI & 0.22 & 4.4 & $r^{2}=0.15$ \\
& & Fasting insulin & 0.15 & 1.9 & $p<0.0001$ \\
\hline
\end{tabular}

Adjustment has been made for BMI, sex, age, (sex*BMI). Intact PI, Fasting intact proinsulin concentration

Table 5. Multiple regression analyses of relationship between concentrations of fasting insulin and des-31,32 proinsulin with lipids and fibrinogen in 218 subjects

\begin{tabular}{llllll}
\hline $\begin{array}{l}\text { Dependent } \\
\text { variable }\end{array}$ & Explanatory variables & & $r$ & $\begin{array}{l}\text { percentage } \\
\text { change in } r^{2}\end{array}$ & $p$ \\
\hline Fibrinogen & In the equation & Fasting insulin & 0.18 & 3 & $r^{2}=0.09$ \\
& Not in the equation & Des-31,32 PI & 0.04 & - & $p=0.0009$ \\
Total cholesterol & In the equation & Fasting insulin & 0.22 & 4.5 & $r^{2}=0.13$ \\
& & Des-31,32 PI & 0.16 & 2.2 & $p<0.0001$ \\
HDL & In the equation & Des-31,32 PI & -0.32 & 8.6 & $r^{2}=0.26$ \\
& Not in the equation & Fasting insulin & -0.10 & - & $p<0.0001$ \\
LDL & In the equation & Des-31,32 PI & 0.23 & 4.6 & $r^{2}=0.15$ \\
& & Fasting insulin & 0.15 & 2 & $p<0.0001$ \\
Triglycerides & In the equation & Des-31,32 PI & 0.26 & 6 & $r^{2}=0.16$ \\
& & Fasting insulin & 0.14 & 1.6 & $p<0.0001$ \\
\hline
\end{tabular}

Adjustment has been made for BMI, sex, age, (sex*BMI). Intact PI, Fasting intact proinsulin concentration

in the renal tubules [17]. Sympathetic nervous system activation by insulin may also provide another amplifier for the interactions between obesity, hyperinsulinaemia and hypertension [18]. It is proposed that in adipose tissue insulin resistance causes excessive non-esterified fatty acid release with a consequent increase in hepatic very low density lipoprotein secretion, but impaired lipoprotein lipase activity in adipose tissue might also contribute to hypertriglyceridaemia and low HDL-cholesterol concentration in insulin resistant states [19].

In population studies direct measures of insulin resistance are difficult to obtain, and insulin concentrations are often used as a surrogate. However, fasting insulin concentrations may be below the limit of sensitivity of some assays and many commercially available assays for insulin also measure intact and des31,32 proinsulins [4]. We have shown, for the first time, in a large homogeneous population of subjects with normal glucose tolerance, that specific measures of fasting and 2-h insulin correlate significantly with insulin resistance syndrome variables, systolic and diastolic blood pressure, triglycerides, and in- versely with HDL-cholesterol. High LDL-cholesterol is not recognised as a component of the insulin resistance syndrome [15]. However, several population studies have shown weak correlations between insulin concentration and LDL-cholesterol [20-22]. Since studies of subjects with isolated elevation of LDL-cholesterol have found no reduction in insulin sensitivity [23], it is not clear what component of this can be explained by the separate association of insulin levels with triglyceride and of triglyceride with LDL-cholesterol. In our population, an independent relation existed between LDL-cholesterol and specific measures of 2-h insulin in normal glucose tolerant subjects, even when adjusting for these confounding variables. Insulin resistance has been found in diabetic $[24,25]$ and non-diabetic [26-28] subjects with microalbuminuria but, using a specific insulin assay, we have not been able to confirm suggestions of associations of hyperinsulinaemia or insulin resistance with albumin excretion rate. In our study, we used both fasting and 2-h insulin concentrations and these provided very similar correlations with the cardiovascular risk factor variables. 
In diabetic populations, and in subjects with impaired glucose tolerance, proinsulin-like molecules comprise a substantial proportion of the total immunoreactive insulin $[4,29]$. In 51 subjects with non-insulin-dependent diabetes mellitus we have reported that, although immunoreactive insulin levels, measured with a commercial radioimmunoassay, correlated with total cholesterol, HDL-cholesterol, triglyceride, systolic blood pressure and diastolic blood pressure, specific insulin concentration remained significantly associated with only triglyceride and blood pressure [3]. In the same subjects, des-31,32 proinsulin correlated significantly with measurements of lipids, as well as blood pressure and plasminogen activator inhibitor type 1 (PAI-1) activity, suggesting that, at least, in diabetic subjects, some of the relationships reported between hyperinsulinaemia and levels of cardiovascular risk factors may actually reflect correlations of these risk factors with elevated concentrations of proinsulin-like molecules.

It may be, however, that in non-diabetic subjects, in whom relative or absolute levels of proinsulin-like molecules are low, similar relationships would not exist, and there would be no confounding by assay nonspecificity, of the relationships with insulin concentrations determined by radioimmunoassay. Two studies in non-diabetic subjects have related proinsulin concentrations to cardiovascular risk factors $[5,6]$. In the first report, from the San Antonio Heart study, concentrations of total proinsulins were shown to be more strongly related to adverse lipid profiles and blood pressure than were those of insulin in $260 \mathrm{Mex}-$ ican-Americans and non-Hispanic whites, with normal or impaired glucose tolerance $(30 \%$ of their study population) [5]. In the second study proinsulins were calculated as the difference between immunoreactive insulin and insulin measured by a specific assay [6]. In our present study we examined these relationships, measuring for the first time specific levels of both intact and des-31,32 proinsulin, in a wellcharacterised population, consisting of larger numbers than in previous studies. We report here only those with normal glucose tolerance, based on World Health Organization criteria [8]. In this study concentrations of proinsulin-like molecules correlated with BMI, age and blood glucose concentration. After correcting for age and BMI, we observed novel, strong correlations between levels of both of the proinsulinlike molecules and lipids, including LDL cholesterol, in the absence of independent associations with blood pressure. While it is possible that these relationships represent confounding by some aspects of obesity, not fully quantified by BMI, such a hypothesis might require computed tomographic scanning to control fully for such measures [30]. Furthermore, it is improbable that controlling for other measures of obesity would differentially influence relationships with insulin and with proinsulin-like molecules, rec- ognising that in multiple regression models, proinsulin-like molecules show stronger relationships than do insulin concentrations with HDL cholesterol, LDL cholesterol and triglycerides. We found, however, that the concentrations of proinsulin-like molecules were too low to confound measured relationships between insulin and the insulin resistance syndrome variables, a point recently confirmed by Haffner et al. [31].

Significant statistical correlation is not proof of causation, so that proinsulin cannot necessarily be implicated directly in determining abnormal levels of risk factors. In intervention studies in diabetic subjects, reducing levels of the proinsulin-like molecules did not affect those of lipids or apoproteins but only those of PAI-1 [32], suggesting the relationship of proinsulin with dyslipidaemia is not causal. Furthermore, the observations of correlations of proinsulin-like molecules at the concentrations found in non-diabetic subjects, which in this study was only $10.1 \pm 7.9 \%$ (mean \pm SD) of those of insulin, when the receptor binding and activity of proinsulin in vitro or in vivo is around $1-8 \%$ of that of insulin [33], makes a direct causative, insulin-like, role of proinsulin improbable. It is possible that borderline beta-cell dysfunction causes lipid abnormalities, which predate glucose, coagulation and blood pressure changes, by mechanisms not involving proinsulin. The relationships of proinsulin concentrations with LDL-cholesterol and fibrinogen, not classically described as variables of syndrome $X$, further suggest that these interactions are unlikely to be mediated by insulin resistance. Studies from Barker's group have shown that low birth weight, or thinness at birth, is associated with high concentrations of intact and des-31,32 proinsulin, PAI-1, insulin resistance and abnormalities of blood pressure and fibrinogen and cholesterol, suggesting one possible mechanism of association [34].

In conclusion, we have shown that in normal glucose tolerant subjects, concentrations of des-31,32 proinsulin are more strongly related to levels of triglyceride, HDL-cholesterol and LDL-cholesterol, and intact proinsulin to fibrinogen, than are those of insulin per se. In these subjects proinsulin concentrations are not significantly related to blood pressure levels after correction for age and BMI, and these relationships may be apparent only in the glucose intolerant state [5]. Moreover, the concentrations of proinsulinlike molecules in normal glucose tolerant subjects are not likely to affect interpretation of previously described relationships between insulin concentrations using standard assays and levels of cardiovascular risk factors [35]. The findings of strong and independent relationships between proinsulin concentrations and insulin resistance syndrome variables raises questions regarding the likelihood of cause and effect. 
Acknowledgements. This study was supported by a grant from the Wellcome Trust. We would like to express our gratitude for support for aspects of this study to Diabetes and Related Diseases Research, to Ms. S. Hammerson and the Mrs. Joan Oliver Bequest. We would also like to thank Eli Lilly for the intact and des-31,32 proinsulin standards.

\section{References}

1. Laakso M, Pyörälä K, Voutilainen E, Marniemi J (1987) Serum lipids and lipoproteins in middle-aged non-insulin dependent diabetic and non-diabetic subjects. Am J Epidemiol 125: 611-621

2. Haffner SM, Fong D, Hazuda HP, Pugh JA, Patterson JK (1988) Hyperinsulinaemia, upper body obesity and cardiovascular risk factors in non-diabetics. Metabolism 37: 338345

3. Nagi DK, Hendra TJ, Ryle AJ Cooper TM, Temple RC, Clark PMS, Schneider AE, Hales CN, Yudkin JS (1990) The relationships of concentrations of insulin, intact proinsulin and 32-33 split proinsulin with cardiovascular risk factors in type 2 (non-insulin-dependent) diabetic subjects. Diabetologia 33: 532-537

4. Temple RC, Clark P, Schneider A, Nagi DK, Hendra TJ, Yudkin JS, Hales CN (1990) Radioimmunoassay may overestimate insulin in non-insulin-dependent diabetics. Clin Endocrinol 32: 689-693

5. Haffner SM, Mykkanen L, Stern MP, Valdez RA, Heisserman JA, Bowsher RR (1993) Relationship of proinsulin and insulin to cardiovascular risk factors in non diabetic subjects. Diabetes 42: 1297-1302

6. Grootenhuis PA, Mooy JM, Popp-Snijders C, Bouter LM, Heine RJ (1993) Proinsulin-like molecules in relation to blood lipids and blood pressure in a general Caucasian population. Diabetologia 36: [Suppl 1] A71 (Abstract)

7. Gould MM, Mohamed-Ali V, Goubet SA, Yudkin JS, Haines AP (1993) Microalbuminura: associations with height and sex in non-diabetic subjects. BMJ 306: 240-242

8. WHO study group (1985) Diabetes mellitus. WHO Technical Report Series 727

9. Friedewald WT, Levy RI, Fredrickson DS (1972) Estimation of the concentration of low-density lipoprotein-cholesterol in plasma, without use of the preparative ultracentrifuge. Clin Chem 18: 499-502

10. Chesham J, Anderton SW, Kingdon CFM (1986) Rapid competitive enzymoimmunoassay for albumin in urine. Clin Chem 32: 669-671

11. Mohamed-Ali V, Yudkin JS (1992) An end-point amplified immunoenzymometric assay (IEMA) specific for human insulin. Clin Sci 82: [Suppl 27] 4P

12. Mohamed-Ali V, Yudkin JS (1993) Simple and highly sensitive microplate immunoradiometric assays (IRMAs) for intact proinsulin and des 31,32 proinsulin. Diabet Med 10: [Supp1 1] P67

13. Sobey WJ, Beer SF, Carrington CA et al. (1989) Sensitive and specific two-site immunoradiometric assays for human insulin, proinsulin, 65-66 split and 32-33 split proinsulin. Biochem J 260: 535-541

14. Johannson A, Stanley CJ, Self CH (1985) A fast, highly sensitive colorimetric enzyme immunoassay system demonstrating benefits of enzyme amplifications in clinical chemistry. Clin Chim Acta 148: 119-124

15. Reaven GM (1985) Role of insulin resistance in human disease. Diabetes 37: 1595-1607
16. Ferrannini E, Haffner SM, Mitchell BD, Stern MP (1991) Hyperinsulinaemia: the key feature of a cardiovascular and metabolic syndrome. Diabetologia 34: 416-422

17. De Fronzo RA, Cooke CR, Andres R, Faloona GR, Davies PJ (1975) The effect of insulin on renal handling of sodium, potassium, calcium and phosphate in man. $\mathrm{J}$ Clin Invest 55: $845-855$

18. Landsberg L (1986) Diet, obesity and hypertension: an hypothesis involving insulin, the sympathetic nervous system and adaptive thermogenesis. Q J Med 61: 1081-1090

19. Frayn KN, Coppack SW (1992) Insulin resistance, adipose tissue and coronary heart disease. Clin Sci 82: 1-8

20. Modan M, Halkin H, Lusky A, Segal P, Fuchs Z, Chetrit A (1988) Hyperinsulinaemia is characterized by jointly disturbed plasma VLDL, LDL and HDL levels. Arteriosclerosis 8: $227-236$

21. Cigolini M, Seidell JC, Charzewska J et al. (1991) Fasting serum insulin in relation to fat distribution, serum lipid profile and blood pressure in European women: the European fat distribution study. Metabolism 8: 781-787

22. Orchard FJ, Becker DJ, Bates M, Kuller LH, Drash AL (1983) Plasma insulin and lipoprotein concentrations: an atherogenic association? Am J Epidemiol 118: 326-337

23. Sheu WHH, Shieh SM, Fuh MMT, Shen DD, Jeng CY, Chen YD, Reaven GM (1993) Insulin resistance, glucose intolerance and hyperinsulinaemia. Hypertriglyceridaemia versus hypercholesterolaemia. Arteriosclerosis Thromb 13: $367-370$

24. Yip J, Mattock MB, Morocutti A, Sethi M, Trevisan R, Viberti GC (1993) Insulin resistance in insulin-dependent diabetic patients with microalbuminuria. Lancet 342: 883-887

25. Groop L, Ekstrand A, Forsblom C, Widén E, Groop PH, Teppo AM, Eriksson J (1993) Insulin resistance, hypertension and microalbuminuria in patients with type 2 (non-insulindependent) diabetes mellitus. Diabetologia 36: 642-647

26. Haffner SM, Stern MP, Gruber KK, Hazuda HP, Mitchell BD, Patterson GK (1990) Microalbuminuria - potential marker for increased cardiovascular risk factors in non diabetic subjects? Arteriosclerosis 10: 727-731

27. Winocour PH, Harland JOE, Millar JP, Laker MF, Alberti KGMM (1992) Microalbuminuria and associated cardiovascular risk factors in the community. Arteriosclerosis 93: $71-81$

28. Woo J, Cocknam CS, Swaminathan R, Lau E, Chan A, Cheung R (1992) Microalbuminuria and other cardiovascular risk factors in non-diabetic subjects. Int J Cardiol 37: 345350

29. Krentz AJ, Clark PMS, Cox L, Nattrass M (1993) Hyperinsulinaemia in impaired glucose tolerance. Clin Sci 85: 97100

30. Bergstrom RW, Newell-Morris LL, Leonetti DL, Shuman WP, Wahl PW, Fujimoto WY (1990) Association of elevated fasting C-peptide level and increased intra-abdominal fat distribution with development of NIDDM in Japanese-American men. Diabetes 39: 104-111

31. HaffnerSM, Mykkanen L, ValdezRA, Stern MP(1994)Evaluation of two insulin assays in insulin resistance syndrome (syndrome X). Arterioscler Thromb 14: 1430-1437

32. Jain SK, Nagi DK, Slavin BM, Lumb PJ, Yudkin JS (1993) Insulin therapy in non-insulin-dependent diabetic subjects suppresses concentrations of proinsulin-like molecules and plasminogen activator inhibitor independently from glycaemic control. Diabet Med 10: 27-32

33. Yudkin JS (1993) Circulating proinsulin-like molecules. J Diab Comp 7: 113-123

34. Barker DJP (ed) (1992) Fetal and infant origins of adult disease. BMJ Press London 